\title{
Action of Thiamine and Related Compounds on Isolated Clam Heart ${ }^{1}$
}

\author{
YASUMI OGURA, JUNKO NARA \\ AND AKemi YAMAgUCHI ${ }^{2}$ \\ Department of Toxicology and Pharmacology, Institute of \\ Food Microbiology, Chiba University, Chiba (Post No. 280)
}

(Received May 13, 1968)

1. The action of thiamine and related compounds on the isolated heart of clam (Meretrix meretrix lusoria) was investigated.

2. S-benzoylthiamine (SBT) and thiamine propyl disulfide (TPD) among these related compounds displayed a very remarkable positive inotropic action, whereas thiamine, acetylthiamine, thiamine diphosphate, thiamine triphosphate, benzoylthiamine monophosphate and ATP did not practically display any clear action.

3. SBT and TPD showed a remarkable antagonistic action against the negative inotropic action of acetylcholine, but have no effect on the action of 5-hydroxytryptamine.

4. The positive inotropic action of SBT and TPD was retained in $\mathrm{K}$-free medium, but it completely disappeared in $\mathrm{Na}$-free or $\mathrm{Ca}$ free medium. When more or less $\mathrm{Na}^{+}$or $\mathrm{Ca}^{2+}$ was present in the medium, the action of SBT and TPD appeared as in the normal medium.

5. The positive inotropic action of SBT and TPD, therefore, is believed to be closely related to the transport system of the cellular membrane of the clam heart muscle, in which $\mathrm{Na}^{+}$and $\mathrm{Ca}^{2+}$ are involved.

Generally, the clam heart muscle is myogenic and consisted of non-striated muscle unlike mammalian heart muscle (1). It is, therefore, of interest from a view-point of pharmacology and physiology that the clam heart reacts on drugs with a special action. Prosser (2) showed that the heart of Venus mercenalia, a clam native to California, was useful in the biological assay of acetylcholine (ACh); Welsh (3), in the biological assay of 5-hydroxytryptamine (5HT); Tanabe et al. (4) that the heart of Mactra sachalinensis, a shellfish native to Japan, and Aishita et al. (5) the heart of Meretrix lusoria, a shellfish native to Japan, were useful in

\footnotetext{
${ }^{1}$ Following abbreviations were used. ACh, acetylcholine; 5-HT, 5-hydroxytryptamine; BOL, 2-bromo $(+)$-lysergic acid diethylamide; LSD, $(+)$-lysergic acid diethylamide; TDP, thiamine diphosphate; TTP, thiamine triphosphate; SBT, $S$-benzoylthiamine; BTMP, benzoylthiamine monophosphate; TPD, thiamine propyl disulfide;

2 小倉保已, 奈良順子, 山口明美
} 
the biological assay of ACh. We also used the heart of clam, Meretrix meretrix lusoria in the biological assay of ACh and 5HT and reported the positive inotropic action of benzylalcohol and related compounds (7). Ogura et al. $(8,9)$ investigated the action of many surface active agents on the clam heart and reported that they produced a negative inotropic action and that there was a relation between negative inotropic action and structure.

In the case of the clam heart, ACh action is not antagonized by atropine (2), not enhanced by anti-cholinesterasic agents and specifically antagonized by mytolon, a muscle relaxant, only $(10,11)$.

It is believed, therefore, that the ACh receptor of the clam heart is nicotinic, but not muscarinic, though an objection was raised to this (12). On the other hand, the positive inotropic action of $5 \mathrm{HT}$ is antagonized by 2-bromo-d-lysergic acid diethylamide (BOL), d-lysergic acid diethylamide (LSD) and ergotamine (13). This is the same as in warm-blooded animals. Cheymol et al. (14) and Ogura (15) investigated the actions of thiamine and related compounds on nerve-muscle preparation (in vivo) of cat and rabbit and found two opposite actions, curare-like and anticurare-like actions, and proposed that these actions might be related with the presence of the ionized nitrogen in the structure of those compounds. In the present paper, the results of comparative study of the actions of thiamine and related compounds on the clam heart are reported.

\section{METHODS}

Clam (Meretrix meretrix lusoria) native to Japan was used throughout the

TABLE 1

Chemical Structures of Thiamine and Related Compounds Used in the Experiment

I. Thiamine group<smiles>CC1=C(CCON)[N+](Cc2cnc(C)nc2N)C=N1</smiles>

(a) $\mathrm{R}=\mathrm{H}$

Thiamine hydrochloride

(b) $\mathrm{R}=\mathrm{COCH}$

Acetylthiamine hydrochloride

(c) $\mathrm{R}=\mathrm{PO}(\mathrm{OH})-\mathrm{O}-\mathrm{PO}(\mathrm{OH})_{2}$

Thiamine diphosphate (TDP)

(d) $\mathrm{R}=\mathrm{PO}(\mathrm{OH})-\mathrm{O}-\mathrm{PO}(\mathrm{OH})-\mathrm{O}-\mathrm{PO}(\mathrm{OH})_{2}$

Thiamine triphosphate (TTP)

II. $S$-acyl-thiamine group

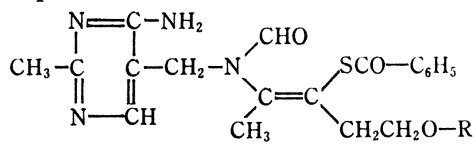

(a) $\mathrm{R}=\mathrm{H}$

$S$-benzoylthiamine hydrochloride (SBT)

(b) $\mathrm{R}=\mathrm{PO}(\mathrm{OH})_{2}$

$S$-benzoylthiamine monophosphate (BTMP)

III. Thiamine alkyl disulfide group<smiles>[R]SSC(CCO)=C(C)N(C=O)Cc1cnc(C)nc1N</smiles>

(a) $\mathrm{R}=\mathrm{C}_{3} \mathrm{H}_{7}$

Thiamine propyl disulfide (TPD) 
experiment. The shells were opened, the heart was isolated and the heart movement recorded on the smoked paper through a lever. The bath volume was $6 \mathrm{ml}$ and the bath was aerated continuously during experiment. The concentration of drugs used in the experiment was the final concentration. The composition ( $\mathrm{g} / \mathrm{liter}$ ) of the artificial sea-water was as follows: $\mathrm{NaCl} 28.5, \mathrm{CaSO}_{4} .2 \mathrm{H}_{2} \mathrm{O} 1.72, \mathrm{MgSO}_{4} .7 \mathrm{H}_{2} \mathrm{O}$ $3.20, \mathrm{MgCl}_{2} .6 \mathrm{H}_{2} \mathrm{O} 8.50, \mathrm{KCl} 0.8, \mathrm{MgBr}_{2}$ 0.1. This solution was adjusted to $\mathrm{pH} 8.2$. The experiment was carried out from spring to summer at room temperature (18-26 $)$.

Chemical structures of thiamine and related compounds used in the experiment are shown in Table 1.

\section{Results}

\section{Proper Action of Thiamine and Related Compounds}

Thiamine - It did not cause any action in concentrations lower than $5 \times 10^{-4}$ $M$. In a concentration of $3 \times 10^{-3} M$ it caused a very slight increase in the amplitude from after $3 \mathrm{~min}$, but the increase was only about $20 \%$ even after $30 \mathrm{~min}$ and the positive inotropic action was immediately recovered by washing (Fig. 1-A).

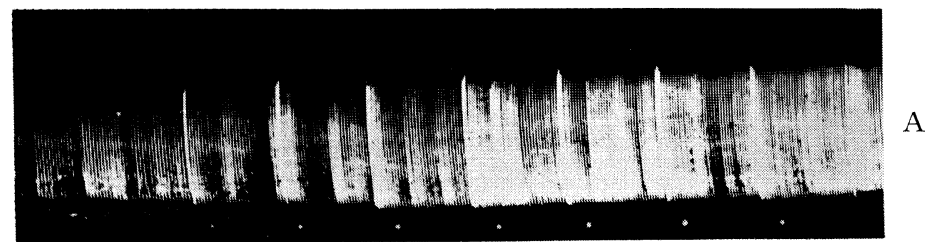

A
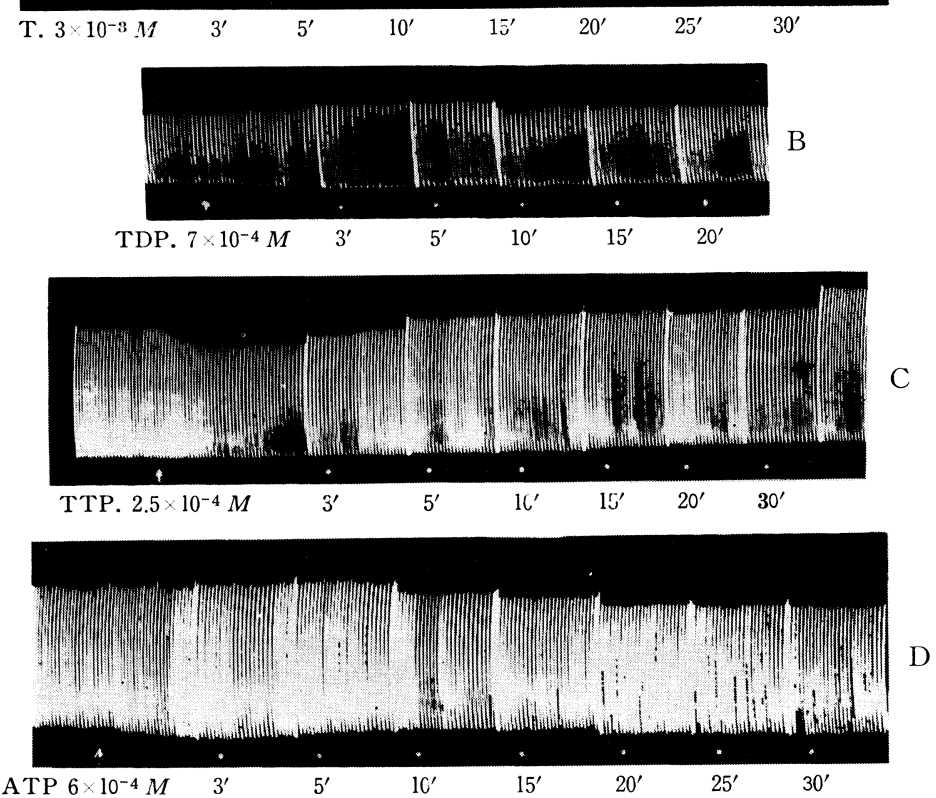

FIG. 1 Effect of Thiamine Related Compounds on the Isolated Clam Heart A: thiamine $3 \times 10^{-3} M, \quad$ B : TPD $7 \times 10^{-4} M, \quad$ C: TTP $2.5 \times 10^{-4} M, \quad$ D : ATP $6 \times 10^{-4} M$. 
Acetylthiamine - - It did not produce any action in concentrations lower than $5 \times 10^{-4} M$. Increase in the amplitude in a higher concentration was almost the same as in the case of thiamine.

Thiamine diphosphate - It did not provoke any action in concentrations lower than $3 \times 10^{-4} M$. A slight increase in the amplitude was noted in a concentration of $7 \times 10^{-4} \mathrm{M}$, but no changes were observed in the heart rate (Fig. 1-B). In any case, the positive inotropic action of thiamine, acetylthiamine and TDP was not notable.

Thiamine triphosphate - It caused a very slight decrease (about $10 \%$ ) in the

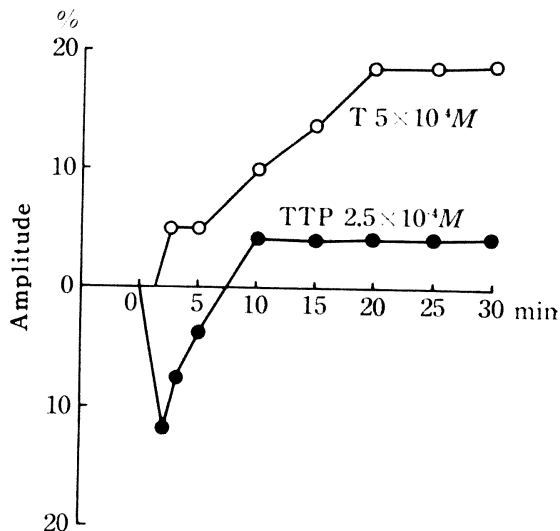

FIG. 2 Changes of Time Course in the Action of Thiamine and TTP on the Amplitude of the Isolated Clam Heart amplitude or in the tonus immediately after addition in a concentration higher than $2.5 \times 10^{-4} M$. This action lasted for 5 to $10 \mathrm{~min}$ and then it was changed to the amplitude increasing action though it was slight (about 5-10\%). Fig. 2 shows the mean of the typical three cases. There were, however, no changes in the heart rate (Fig. 1-C). Since depression of the amplitude was noted in the early stage with TTP unlike thiamine, acetylthiamine and TDP, ATP in equimolar concentrations were investigated. As shown in Fig. 1-D, a slight increase in the amplitude was noted for $10 \mathrm{~min}$ after addition but it was gradually decreased. The extent of decrease was about $20 \%$ even after $30 \mathrm{~min}$. The mechanism of the decreasing action of TTP is unknown at present, though it may be ascribed to triphosphate ester.

S-benzoylthiamine - It did not cause any remarkable action in concentrations lower than $3 \times 10^{-5} \mathrm{M}$, but caused increase in the amplitude immediately after addition to a concentration of $3 \times 10^{-4} \mathrm{M}$. It gradually increased reaching a peak in 15 to $30 \mathrm{~min}$. This action was very remarkable to give rise to a very slight
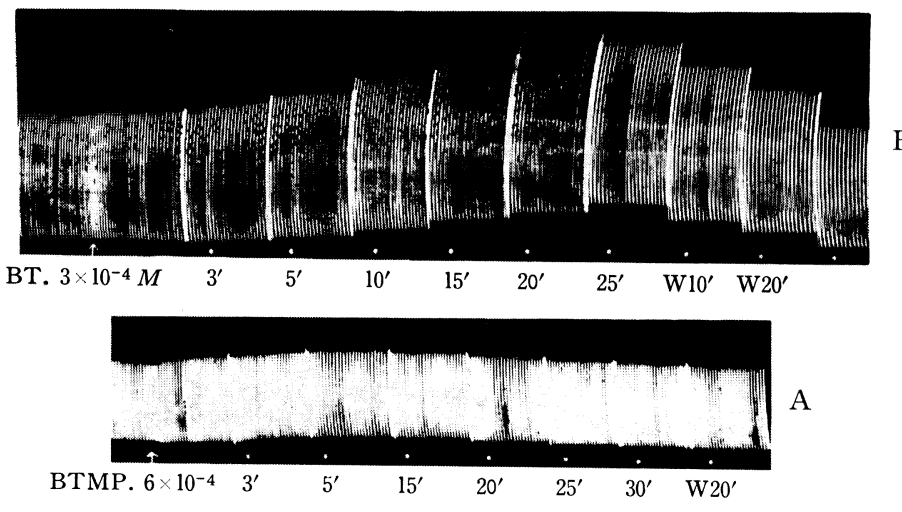

FIG. 3 Action of SBT, BTMP on the Isolated Clam Heart $\mathrm{BT}$, SBT : $3 \times 10^{-4} M$, BTMP : $6 \times 10^{-4} M$. 


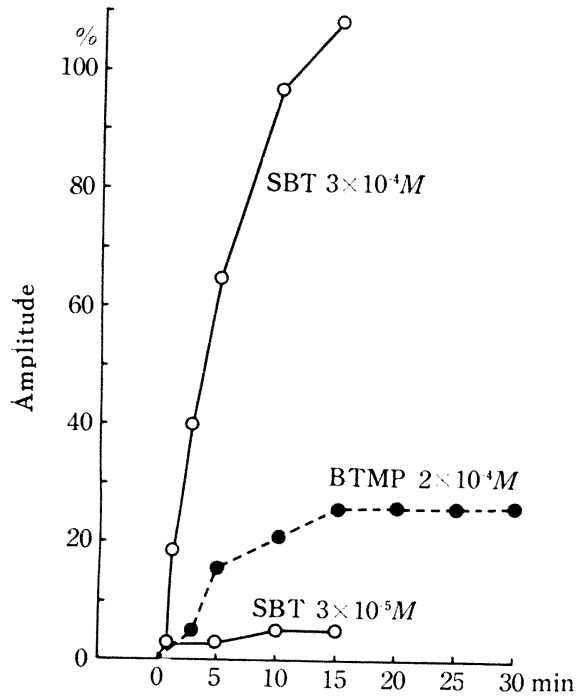

FIG. 4 Changes of Time Course in the Action of SBT and BTMP on the Amplitude of the Isolated Clam Heart reduction in the heart rate together with an increase in the amplitude. Occasionally, an appreciable increase in the tonus was noted together with increase in the amplitude (Fig. 3-A). The increased amplitude could be reduced to the previous level before addition of SBT in 20 to $30 \mathrm{~min}$ by several times of washing.

Benzoylthiamine monophosphateIt caused a very slight increase in the amplitude and tonus in a concentration of $2 \times 10^{-4} M$, though the changes were not clear (Fig. 4). The action was not increased by increasing the concentration to $6 \times 10^{-4} M$ and more (Fig. 3-B).

Thiamine propyl disulfide - It Iid not cause any notable changes in concentrations lower than $3 \times 10^{-5} \mathrm{M}$, caused an about $10 \%$ increase in the amplitude in a concentration of $3 \times 10^{-4} \mathrm{M}$, a very re-

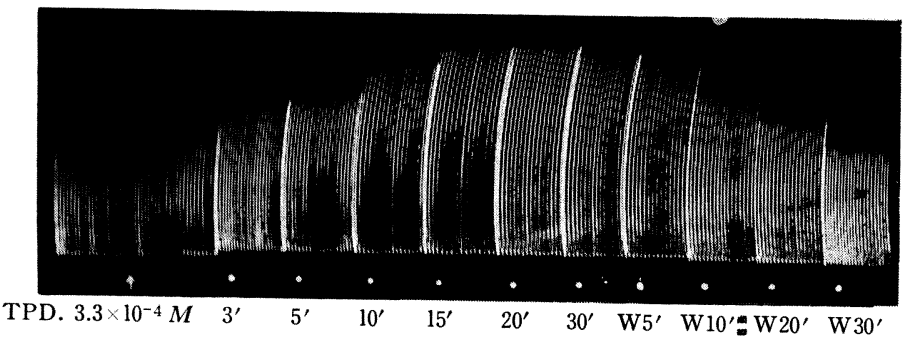

FIG. 5 Action of TPD of Isolated Clam Heart

markable increase in the amplitude immediately after addition reaching a peak in 15 to $30 \mathrm{~min}$ in a concentration of $3.3 \times 10^{-4} M$. No striking changes in the heart rate were noted (Fig. 5). These changes resembled closely those of SBT. To reduce the amplitude to the previous level before addition of TPD by washing, 30-40 min was required.

2. Antiacetylcholine Action of SBT and TPD

ACh causes decrease in the amplitude in a low concentration and diastolic stop of the clam heart in a high concentration. Both SBT and TPD caused a very

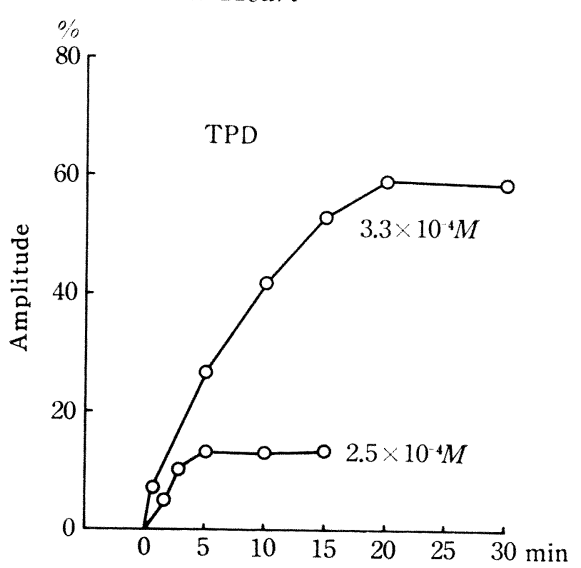

FIG. 6 Changes lof Time Course in the Action of TPD on the Amplitude of the Isolated Clam Heart 


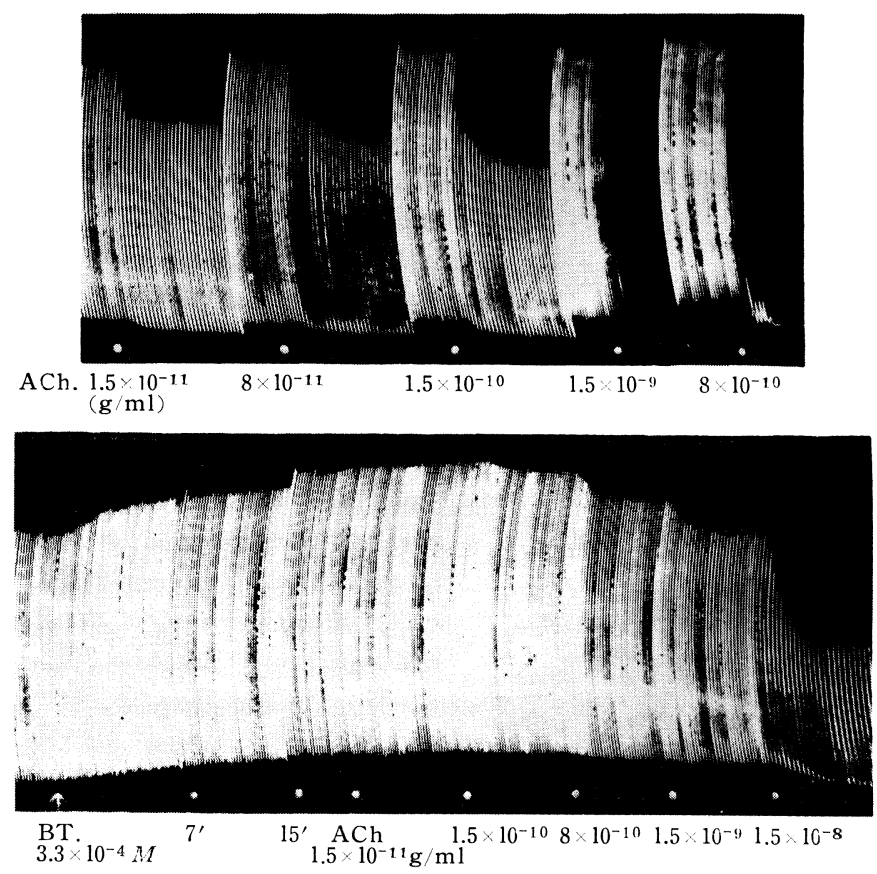

FIG. 7 Inhibitory Action of SBT on the Negatiive Inotropic Action of ACh BT, SBT : $3.3 \times 10^{-4} M$.
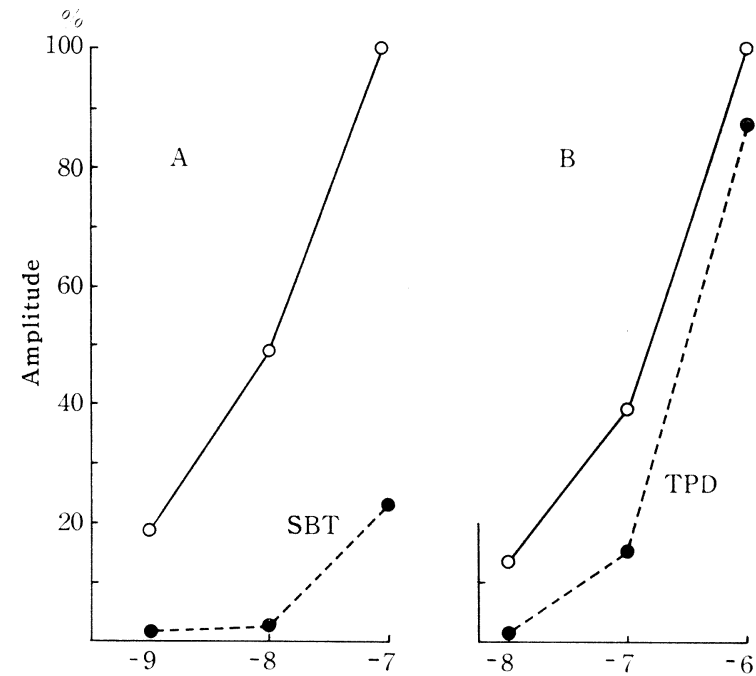

FIG. 8 Effect of SBT and TPD on the Doseresponse Curve of $\mathrm{ACh}$

Abscissa: concentration of $\mathrm{ACh}$ in $\log$ scale. remarkable antagonistic action against this action of $\mathrm{ACh}$ in a concentration higher than $3.3 \times 10^{-4} M$ and their action was most clear when the increase in the amplitude reached a peak. A cardiac stop caused by the highest concentration of ACh was also inhibited even after appearance of the remarkable positive inotropic action of SBT. Such an action of SBT seemed to be stronger than TPD (Fig. 7). Recovery of the action of ACh after washing was related with the rate of disappearance of the positive inotropic action of SBT or TPD. Such an antiacetylcholine action was not noted in thiamine related compounds other than SBT and TPD. 


\section{Effect of SBT and TPD on the Action of $5 H T$}

As well known, 5HT causes increase in the contraction of the clam heart, very slightly in a concentration of $10^{-9} \mathrm{~g} / \mathrm{ml}$ and somewhat remarkably in a concentration of $10^{-8} \mathrm{~g} / \mathrm{ml}$. This action of $5 \mathrm{HT}$ was not increased or inhibited by pretreatment with SBT or TPD in a concentration higher than $3 \times 10^{-4} M$ for $15-30 \mathrm{~min}$, and cardiac stop by $5 \mathrm{HT}$ in a high concentration also was not affected.

\section{Action of SBT and TPD in K-free Solution}

Even when the clam heart was placed in K-free solution, the positive inotropic action of SBT was produced without being inhibited, it often accompanied the augmentation of the tonus.

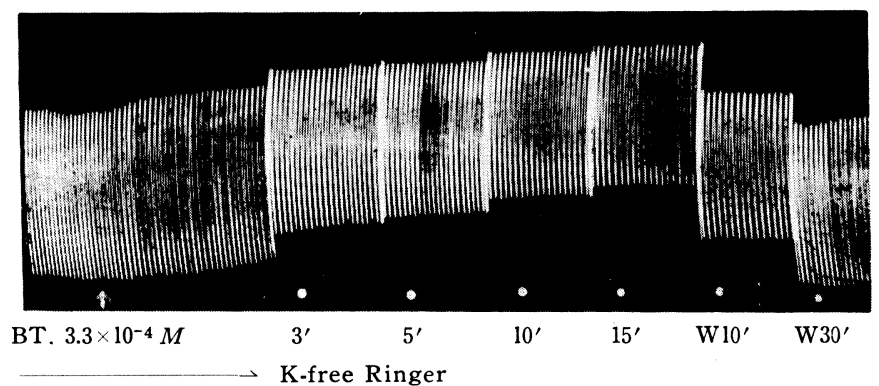

FIG. 9 Action of SBT in K-free Solution BT, SBT : $3.3 \times 10^{-4} M$.

\section{Effect of $\mathrm{Ca}$ Ion on the Action of SBT and TPD}

Both SBT and TPD caused a positive inotropic action in $1 / 3 \mathrm{Ca}$ containing solution (the content of $\mathrm{CaSO}_{4} \cdot 2 \mathrm{H}_{2} \mathrm{O}$ in normal artificial sea-water was reduced to 1/3) (Fig. 10). In Ca-free solution (prepared by eliminating $\mathrm{Ca}^{2+}$ from normal artificial sea water), however, the movement of the clam heart was remarkably depressed in the amplitude and heart rate and arrythmia was induced at times. The positive inotropic action of SBT and TPD on the clam heart under such a condition could not be noted (Fig. 11).

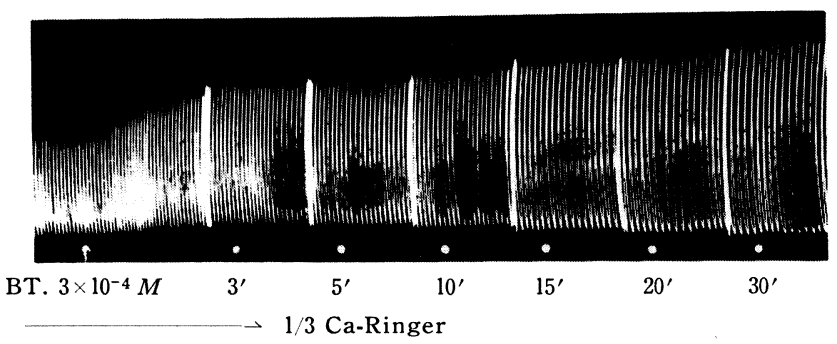

FIG. 10 Action of SBT in 1/3 Ca-containing Solution BT, SBT : $3 \times 10^{-4} M$. 

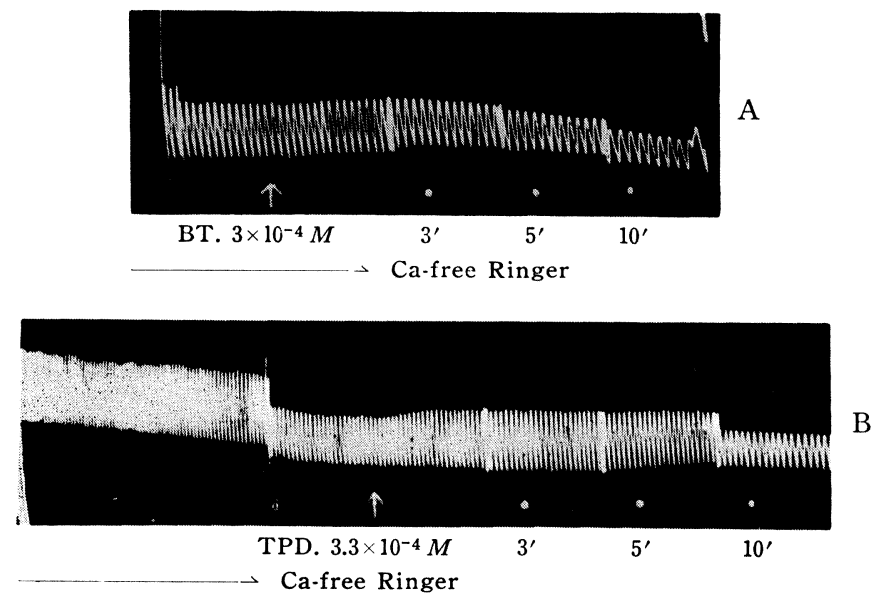

FIG. 11 Action of SBT and TPD in Ca-free Solution BT, SBT : $3 \times 10^{-4} M$, TPD : $3.3 \times 10^{-4} M$.

\section{Effect of $\mathrm{Na}$ Ion on $S B T$ and $T P D$}

In $1 / 3 \mathrm{Na}$ containing solution or in $\mathrm{Na}$-free solution, the movement of the clam hearrt was depressed in the amplitude and in a short time resulted in cardiac stop, but when $2 / 3 \mathrm{Na}$ containing solution was used, apparent changes in the cardiac movement were not noted.
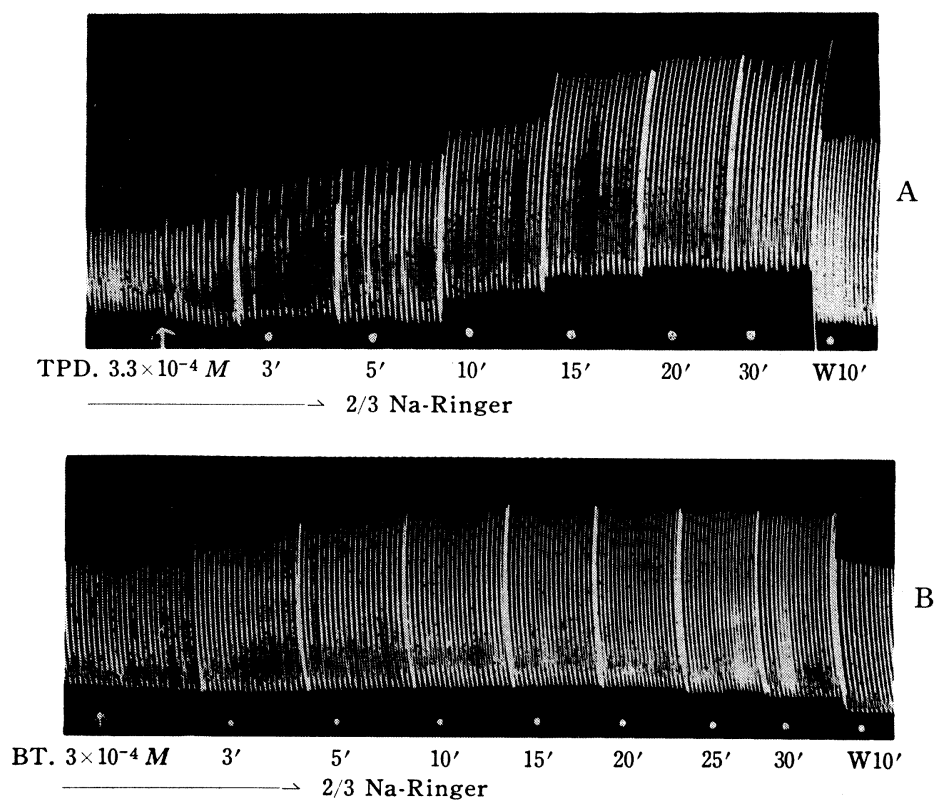

FIG. 12 Action of TPD and SBT in 2/3 Na-Containing Solution TPD $: 3.3 \times 10^{-4} M$, BT : SBT $3 \times 10^{-4} M$. 
After cardiac stop produced in $1 / 3 \mathrm{Na}$ containing solution or in $\mathrm{Na}$-free solution, both SBT and TPD could not produce their positive inotropic action. In $2 / 3$ $\mathrm{Na}$ containing solution, however, they caused positive inotropic action as in normal artificial sea-water (Fig. 12). TPD often caused increase in the tonus as shown in Fig. 12-A.

\section{Discussion}

The effect of seven compounds related to thiamine on the clam heart was investigated. A very strong positive inotropic action was noted in SBT and TPD. This action did not appear in Na-free or Ca-free solution, but appeared in K-free solution. This action was also completely retained in $1 / 3 \mathrm{Na}$ containing solution and $2 / 3 \mathrm{Ca}$ containing solution. Such a phnomenon seems to be similar to that of excitability of the smooth muscle as like taenia coli or skeletal muscle of crayfish (16). This may be related to the fact that the heart of Meretrix meretrix lusoria is myogenic and consisted of non-striated muscle cells.

Nakazawa et al. (17) found that both TPD and TTFD caused prolongation of the repolarization phase and inhibition of $\mathrm{Ca}$ influx in the heart muscle cell of the guinea-pig by means of electrophysiological method, but thiamine did not possess such action. Misu et al. (18) also reported almost similar results. Kanno (19) and Nakazawa et al. (17) reported that TPD and thiamine tetrahydrofurfuryl disulfide caused the positive inotropic action in the isolated guinea-pig atria. Katsura et al. (20) also recognized the same results in the toad heart. These results are closely similar to those obtained in our experiment of the clam heart.

There is, however, a great difference in the reactivity to drugs between the heart of vertebrate and that of clam. In the case of the latter, the negative inotropic action of $\mathrm{ACh}$ is not antagonized by curare, pentamethonium and atropine, not increased by eserine, but antagonized by only mytolon and tetraethylammonium $(21,10)$. Luduena et al. (11) suggested that such an antiacetylcholine action of mytolon was not related to its ganglion blocking action, curare-like action or ACh-esterase inhibiting action. The antiacetylcholine action of SBT and TPD observed in the present experiment, therefore, may not be the antagonism to the ACh receptor. Moreover, such an action of SBT and TPD is not caused by their action on the $5 \mathrm{HT}$ receptor, because the action of $5 \mathrm{HT}$ is not enhanced or inhibited by SBT and TPD. It also can be shown by the facts that SBT do not possess any $5 \mathrm{HT}$-like action in vertebrates and invertebrates and that they are not antagonized by $5 \mathrm{HT}$ antagonists. The positive inotropic action of SBT and TPD, therefore, is believed to be closely related to the excitability of the cell membrane in which $\mathrm{Na}^{+}$and $\mathrm{Ca}^{2+}$ play an important role.

It is of interest to analyse the action of thiamine and related compounds on the clam heart from the view-point of chemical structure-activity relationship. The positive inotropic action becomes appresiable when the thiazole nucleus is fissured as in SBT and TPD no distinct difference in the action is noted between SBT and TPD. It can be shown that the pyrimidine nucleus not necessarily plays an important role to increase the contractile force by the fact that thiamine and acetylthiamine have no remarkable positive inotropic action. 
When these compounds are phosphorylated, the original action is reduced or disappears. For example, BTMP, a monophosphate of SBT, does not provoke the positive inotropic action as shown in SBT. Such a phenomenone also could be recognized between thiamine and TDP or TTP. These results correspond well with the fact that phosphorylation caused decrease in or disappearance of the recurarisation inducing action and histamine releasing action of thiamine related compounds as already reported by the authors (15).

The present experiment was carried out with preparation placed in a medium of high $\mathrm{pH}$ as 8.3 unlike in the case of isolated organs of warm-blooded animals. In our experiment of the isolated guinea-pig atria, both SBT and TPD caused decrease in the amplitude when $\mathrm{pH}$ was below 7.0, while they caused increase when $\mathrm{pH}$ was higher than 7.0 (not published). According to Satoh (22), the rat's liver tryptophan pyrrolase activity was enhanced by TPD and TTFD when $\mathrm{pH}$ was higher than 8.0. In view of these facts, the positive inotropic action of SBT and TPD on the clam heart may be ascribable to the dependability to $\mathrm{pH}$.

\section{ACKNOWLEDGEMENT}

We should like to express our thanks to Sankyo Co. Ltd. for the offer of acetylthiamine hydrochloride, TTP, SBT, and BTMP, and to Takeda Chemical Industries, Ltd. for the offer of thiamine, TDP and TPD.

\section{REFERENCES}

1. Prosser, C. L., Comparative Animal Physiology, p. 76, W. B. Saunders Co., (1962).

2. Prosser, C. L., Biol. Bull., 78, 72 (1940).

3. Welsh, J. H., Arch. Exp. Path. Pharmakol., 219, 23 (1953).

4. Tanabe, T., and Sato, M., Seitai-no-Kagaku, 4, 135 (1952).

5. Aishita, H., Segawa, T., and Takagi, H., Folia pharmacol. japon., 61, 16 (1965).

6. Ogura, Y., Mori, Y., and Watanabe, Y., J. Pharmac. exp. Ther., 154, 456 (1966).

7. Ogura, Y., and Nara, J., Folia pharmacol. japon., 61, 126 (1965).

8. Ogura, Y., and Nara, J., Ann. Rept. Inst. Food Microbiol. (Chiba Univ.), 17, 45 (1964).

9. Ogura, Y., and Tamura, J., Ann. Rept. Inst. Food Microbiol. (Chiba Univ.), 20, 95 (1967).

10. Florey, E., and Merwin, H. J., Nervous Inhibition, p. 13, Pergamon Press, 1961.

11. Luduena, F. P., and Brown, T. G. Jr., J. Pharmac. exp. Ther., 105, 232 (1952).

12. Welsh, J.H., and Taub, R., Brit. J. Pharmacol., 8, 327 (1953).

13. Greenberg, M. J., Brit. J. Pharmacol., 15, 375 (1960).

14. Cheymol, J., Bourillet, F., Levassort, C. et Kerp, L., Arch. int. Pharmacodyn., 3, 36 (1957).

15. Ogura, Y., Abstract of XIX Japanese Pharmaceutical Congress, p. 150, (1964).

16. Ogura, Y., Watanabe, Y., and Mori, Y., Folia pharmacol. japon., 60, 128 (1964).

17. Nakazawa, Y., and Ueno, A., Jap. J. Pharmacol. 15, 10 (1965).

18. Misu, Y., Takaori, S., and Shimamoto, K., Jap. J. Pharmacol., 15, 257 (1965).

19. Kanno, M., Jap. J. Pharmacol., 16, 327 (1966).

20. Katsura, H., and Murai, J., Vitamins, 30, 262 (1964).

21. Faenge, R., Pharmacol. Rev., 14, 281 (1962).

22. Satoh, T., Jap. J. Pharmacol., 18, 373 (1968). 